\title{
Asociacionismo como Instrumento de Participación y Ejercicio del Poder en Maracaibo, Venezuela (1880-1910)
}

\section{Associationism as an Instrument of Participation and Exercise of Power in Maracaibo, Venezuela (1880-1910)}

http://dx.doi.org/10.17981/cultedusoc.12.2.2021.10

Recibido: 15 de octubre de 2020 Aceptado: 28 de enero de 2021 Publicado: 1 de julio de 2021.

Jairo Enrique Boscán-Fernández

Universidad del Zulia. Núcleo Punto Fijo (Venezuela)

jairoboscanluz@gmail.com

Xiomara Emilia Guanipa-de-Dávila

Universidad del Zulia. Núcleo Punto Fijo (Venezuela)

xiomydaguanipa@hotmail.com

Para citar este artículo:

Boscán-Fernández, J. y Guanipa-de-Dávilam, X. (2021). Asociacionismo como Instrumento de Participación y Ejercicio del Poder en Maracaibo, Venezuela (1880-1910). Cultura, Educación y Sociedad, 12(2), 165-180. DOI: http://dx.doi.org/10.17981/ cultedusoc.12.2.2021.10

\section{Resumen}

En el artículo se interpreta el fenómeno del asociacionismo como instrumento de poder en los actores económicos de Maracaibo (Venezuela) en el período 1880 . 1910, sustentado en el adelantamiento de una política de modernización y el otorgamiento de mayor amplitud a la libertad individual. Desde estas prácticas se configura una estrecha relación entre los funcionarios del Estado e inversionistas ingleses, alemanes, y franceses, planteando el financiamiento y ejecución de obras para el bienestar público. Esta realidad expresa el desarrollo ideológico de los maracaiberos de la época, vinculado con la penetración del liberalismo y el positivismo como corrientes del pensamiento. La investigación es de naturaleza hermenéutica explicativa, cuyos datos emanan del Archivo Histórico del Zulia (Venezuela), Centro de Investigaciones Documentales Históricas del Zulia y fuentes secundarias. Los resultados permiten comprender el significado del asociacionismo en la región geo-histórica marabina como herramienta promotora de prácticas sociales y patrones culturales, desde los cuales emerge una concepción del espacio público para el disfrute, la realización de obras y el ejercicio del poder, amparado en un discurso altruista alineado con la prédica del bien común. Se concluye en una noción de poder asociado a términos de producción que sobrepone la libertad a la represión, la promoción a la prohibición y la recompensa al castigo.

Palabras clave: Asociacionismo; instrumento de participación; espacio público; ejercicio del poder

\section{Abstract}

The article interprets the phenomenon of associationism as an instrument of power in the economic actors of Maracaibo (Venezuela) in the period 1880-1910, supported by the advancement of a modernization policy and the granting of greater scope to individual freedom. From these practices, a close relationship is formed between State officials and English, German, and French investors, proposing the financing and execution of works for the public welfare. This reality expresses the ideological development of the maracaiberos of the time, linked to the penetration of liberalism and positivism as currents of thought. The research is of an explanatory hermeneutical nature, whose data emanate from the Historical Archive of Zulia (Venezuela), Center for Historical Documentary Research of Zulia and secondary sources. The results allow us to understand the meaning of associationism in the geo-historical marabina region as a tool to promote social practices and cultural patterns, from which a conception of public space emerges for the enjoyment, the realization of works and the exercise of power, protected in an altruistic discourse aligned with the preaching of the common good. It concludes in a notion of power associated with terms of production that superimposes freedom over repression, promotion over prohibition, and reward over punishment.

Keywords: Associationism; instrument of participation; public space; exercises of power 


\section{INTRODUCCIÓN}

El artículo interpreta el surgimiento de las diferentes modalidades de asociación como instrumento de ejercicio del poder de los actores económicos y sociales en Maracaibo (Venezuela) en el período 1880-1910, tomando en cuenta el auge que experimentaron diversas formas asociativas desde el surgimiento de organizaciones de distinta índole que llegan a establecer fuertes relaciones con funcionarios del Estado local, planteando una política de modernización con la ejecución de obras para el bienestar público. Se asume el asociacionismo cono una estrategia de organización que a partir de la formación de un conjunto de modalidades (gremios, sociedades, juntas, clubes, cofradías), fomentaba la reunión de un grupo de individuos con posiciones comunes, a fin de promover la lucha por salvaguardar sus privilegios económicos, políticos o culturales, frente a las decisiones emanadas del poder público.

En este sentido, el asociacionismo es producto de la modernidad y de la disolución del antiguo régimen europeo; quienes han abordado el estudio de las últimas décadas del siglo XIX coinciden en señalarlas como la Edad de Oro de Maracaibo, determinada por una serie de procesos que maduran de manera definitiva en estos años. En el marco de este momento estelar, irrumpe la cultura asociativa como expresión del nivel de desarrollo ideológico e intelectual que habían alcanzado los actores del espacio público zuliano de la época, con un alto sentido de conciencia acerca de su papel de dinamizadores del proceso de construcción de una sociedad sustentada en los valores de modernidad que imperaban en el mundo, circunstancia que refuerza el sentido de identidad regional que, aún hoy día, distingue a sus habitantes.

Las sociedades de pensamiento se constituyeron en la práctica asociativa más relevante, ellas representaban un nuevo tipo de sociabilidad a través de la cual la población encontró formas de organización que posibilitaron redefinir los patrones de relación con los integrantes del Estado; constituidas por actores sociales de tipo antiguo se pensaban como un gran cuerpo con órganos diferentes y funciones diversas: un conjunto de estamentos, corporaciones y comunidades políticas diversas, cada uno con sus derechos y deberes específicos, con sus privilegios, sus leyes propias, que definen su situación en relación con los otros grupos y con el Estado (Guerra, 1998).

En consecuencia, ser miembro de una sociedad de pensamiento implicaba reunir una serie de cualidades en el orden moral, intelectual y económico, al parecer no todo los ciudadanos estaban capacitados para formar parte de éstas, se debía poseer una elevada posición cultural, ideológica y bienes de riquezas. Eran individuos que con preparación y posesiones establecerían fuertes vínculos con funcionarios públicos, diseñando y orientando la puesta en práctica de políticas e iniciativas que favorecieran a los reconocidos miembros de la sociedad actuando como entes asociados, para luego prestar auxilio a los desventurados, aquellos que por diversas razones no gozaban de los beneficios que éstos si poseían, a través de obras e iniciativas asistencialistas públicas y privadas.

Se trataba de utilizar las necesidades propias y ajenas para configurar una línea de acción conducente a traducirse en factores propiciadores de soluciones, donde además de asumir un papel protagónico y generar actitudes de liderazgo, se estaban adquiriendo posiciones políticas que al influir sobre las decisiones del sector público conducían, dentro de la 
filosofía asistencialista de un Estado Liberal, al desarrollo de un conjunto de obras donde mayormente la inversión procedía del ejecutivo, pero administrada, ejecutada y supervisada por esos entes privados, quienes al final obtenían beneficios materiales tras esa proclama altruista que en apariencia orientaba su accionar.

El individuo asociado marabino del siglo XIX se puede caracterizar a partir de la identificación de los siguientes atributos:

- Elevada formación intelectual y condición moral.

- Individuo joven, generalmente del sexo masculino.

- Privilegiada posición económica.

- Con formación política.

- Habitante de la ciudad con una línea de ascendencia reconocida.

En esta perspectiva, se precisa reconocer la actuación de los diferentes actores protagónicos de la época en el contexto de los hechos abordados; donde se propicia la configuración de redes sociales derivadas de las múltiples relaciones entre sujetos, dándole forma y sentido al ejercicio del poder de acuerdo a determinados intereses individuales, grupales o colectivos.

\section{REVISIÓN DE LA LITERATURA}

Se parte de la concepción del asociacionismo como un producto de la modernidad y consecuentemente de la disolución del antiguo régimen europeo, donde según Maza (2003):

Los estudios antropológicos sobre el asociacionismo han aportado también una ampliación de su significación más allá de su consideración como vehículos para la participación social y política de los ciudadanos. Las asociaciones, sus tipos, formas, características y funciones aparecen como aspectos importantes de la cultura política de cada sociedad, adquiriendo en ocasiones el carácter de auténticos marcadores de la especificidad diferenciada de la misma: cofradías andaluzas, sociedades gastronómicas vascas, sociedades excursionistas catalanas, peñas taurinas navarras, asociaciones musicales valencianas, son algunos ejemplos (p. 13).

Evidencia concreta de la aparición de esta cultura asociativa lo constituye el surgimiento de una serie de organizaciones económicas donde se reunían los prósperos hombres del comercio de la época para compartir sus intereses y visiones acerca del resguardo de privilegios económicos, sociales y políticos, siempre mancomunados en el manejo de un discurso altruista apalancado en la promoción del bien común. Ortiz (2015) reafirma la importancia de este proceso cuando nos relata que:

En 1882, se abría al público el Banco de Maracaibo, entidad financiera que imprimía su propio papel moneda, siendo pionera en el crédito agropecuario. Igualmente se creó en 1880 la compañía de Seguros Marinos, junto a la Cámara de Comercio y el Club de Comercio (p. 122).

En el contexto de la irrupción de este fenómeno en la realidad zuliana de finales del siglo $\mathrm{XX}$, se considera relevante el manejo de un conjunto de categorías que por su relevancia en la comprensión de los procesos espaciales, económicos, sociales, políticos y culturales, se traducen en referencia obligada de todo estudio de carácter regional como el presente. Es el caso de la región Geo-Histórica Marabina, que en la perspectiva de Cardozo (1991): 
Expresa la existencia de un área con características históricas comunes, producto de la gestación de vínculos económicos y socio-culturales entre los paisajes que la componen y por la influencia de una ciudad que actúa como centro jerarquizante”. Estamos hablando de Maracaibo como una ciudad-puerto que asumió durante el siglo XIX el liderazgo del desarrollo regional, occidental e incluso del nororiente colombiano, facilitado por su estratégica ubicación que le permitió convertirse en ruta marítima obligada del comercio caribeño hacia Norteamérica y Europa (p. 7).

De igual manera toma auge en aquella época la visión de Autonomía Regional; producto de las políticas Guzmancistas de atropello a la soberanía del Zulia como entidad federal comienza a gestarse una verdadera conciencia autonómica en los zulianos, quienes desde diversos espacios presionan a través de un coherente discurso político la devolución de la soberanía perdida, estos ciudadanos se agruparon fundamentalmente en formas de organización políticas y económicas creadas para la época, como producto del desarrollo ideológico de las elites zulianas en torno a las modernas corrientes del pensamiento liberal dominante en los grandes centros económicos capitalistas de ese momento.

Se constituye, en principio, esta prédica autonomista en una cuestión de identidad individual al construir el sujeto representaciones de sí mismo, para luego incorporar elementos relacionados con modelos construidos en el marco de las interacciones sociales y las negociaciones voluntarias o impuestas que éstas determinan, influenciadas por las luchas y estrategias de los grupos que compiten por el control cultural. Estos modelos de identidad socialmente producidos en el contexto del proceso de irrupción del fenómeno del asociacionismo en la realidad zuliana de finales del siglo XIX, incluyen las identidades religiosas, étnicas y nacionales; representaciones colectivas que son interiorizadas en mayor o menor grado, de una u otra forma, por los diferentes miembros de la sociedad (Rubio, 2007).

Finalmente se menciona como categoría estructurante del abordaje la Opinión Pública, considerando el hecho de desarrollarse en este período una verdadera revolución de las ideas en los grupos que liderizaban los procesos políticos y económicos. Estos expresan puntos de vista influyentes en el desarrollo histórico marabino, favorecido por iniciativas concebidas como causa y consecuencia de ese despertar ideológico, esto es, el surgimiento de los gremios y sociedades del pensamiento como espacios para la discusión y propuestas en torno a la dinámica de funcionamiento de la sociedad zuliana con la proyección de esas ideas al colectivo, a través del florecimiento de la prensa como canal natural para la información de aquellos temas de interés general, habiendo asumido la mayoría de los órganos periodísticos existentes para la fecha una clara posición de enfrentamiento a las políticas centralistas que buscaban limitar la soberanía del Zulia.

\section{Metodología}

La investigación de naturaleza hermenéutica interpretativa se ubica en el área del conocimiento histórico, circunstancia que promueve su realización a partir de las orientaciones propias de la tradición histórica que opera con las pautas de la investigación social científica con sus procedimientos y técnicas, sistematizadas de la siguiente manera: 
- Ubicación, selección, recopilación y arqueo de las fuentes documentales primarias y secundarias.

- Estudio de la información obtenida a partir de las fuentes a través de los diversos instrumentos de registro y análisis de datos diseñados para tal fin.

- Desarrollo del discurso final de acuerdo a las exigencias del método.

La Hermenéutica como método interpretativo de datos históricos y filosóficos se encuentra estrechamente ligada al arte de la revisión de textos y documentos antiguos. Desde la perspectiva de Gadamer (2000), constituye el procedimiento que permite expresar la universalización de la capacidad interpretativa desde lo personal y especifica historicidad; ésta provee herramientas para comprender a un autor mejor de lo que pudieron hacerlo sus contemporáneos. De las diversas concepciones de esta tradición metódica se asume la hermenéutica de Dilthey (1949), quien asume a esta disciplina como el método propio de las ciencias del espíritu, al ser capaz de contextualizar todo conocimiento humano a procesos vitales e históricos. "El concepto de historicidad desarrollado por Dilthey concebirá un ser que se construye a través de la historia, que tiene un pasado, se proyecta al futuro y permanece en un aquí y ahora" (Calderón, 2013, p. 11).

De acuerdo a esa configuración metodológica la investigación reúne las siguientes características:

- Es de carácter deductiva e interpretativa.

- En atención a la estrategia empleada para el desarrollo del proceso de indagación se concibe como documental.

- El campo de los hechos bajo estudio se refiere al surgimiento de las diferentes modalidades de asociación como instrumento de ejercicio del poder de los marabinos en el período 1880-1910.

Los sujetos de investigación fueron los actores que integraron las sociedades que se constituyeron en Maracaibo, Venezuela, en dicho período. La muestra estuvo representada por los sujetos pertenecientes a las sociedades que ejercitaron el asociacionismo, éstas se localizaron durante el proceso de ubicación de las fuentes de información de índole primaria y secundaria.

En la perspectiva de las fuentes de información empleadas, la investigación se apoyó en el análisis de datos provenientes de documentos ubicados en el Archivo Histórico del Zulia (AHZ) y Centro de Investigaciones Documentales Históricas del Zulia (CIDHIZ), donde se extrajeron los siguientes datos:

- Los Comerciantes, industriales y establecimientos mercantiles instalados en la región durante el período en estudio.

- Las actas constitutivas de las diferentes sociedades que se fundaron en ese momento, que ilustran acerca de sus integrantes, características y propósitos.

- Las Comunicaciones cruzadas entre los integrantes de esas organizaciones y los funcionarios del Estado, donde se perciben las connotaciones del discurso de los hombres de negocios e intelectuales de la época y su estrecha relación con el sector público. 
Esta información fue trabajada con el adecuado apoyo de materiales secundarios, representados por la producción intelectual del Centro de Estudios Históricos del Estado Zulia y otras referencias bibliográficas e informáticas.

\section{Resultados}

El asociacionismo como expresión de la voluntad de los individuos de agruparse en torno al ejercicio de una actividad tiene su origen en los gremios de la edad media, constituyéndose con el advenimiento del capitalismo en un instrumento de sociabilidad moderna protegido por el Estado, con quien establece fuertes vínculos para el desarrollo de políticas públicas En España se comienza a expresar una voluntad asociativa en la ciudad de Barcelona desde la Alta Edad Media, expresado en el surgimiento de una serie de modalidades que participaban activamente en la vida pública, constituyéndose en instrumentos ejecutores de políticas asistencialistas inspiradas en motivaciones religiosas.

En un primer momento, éstos se organizaron alrededor de las cofradías, asociaciones profesionales bajo la advocación de un santo patrón que realizaban funciones puramente religiosas, benéficas y asistenciales, como podrían ser celebrar la festividad del santo patrón y difundir su culto o promover la caridad hacia pobres y enfermos. Posteriormente las mismas fueron pasando a ocuparse también de temas económicos y políticos, y en este punto tuvieron su origen los denominados gremios (Bernaus, 2000, p. 1).

En Hispanoamérica la herencia de las sociedades españolas se traslada a partir de finales del siglo XVIII, teniendo en las publicaciones periódicas su principal instrumento de proyección. Maracaibo representa para finales del siglo XIX un espacio de gran dinamismo comercial, educativo e ideológico, influenciado por los principios del capitalismo mundial, propiciando el surgimiento de una intelectualidad que asume el papel de transformar las estructuras arcaicas heredadas del antiguo régimen colonial a una realidad moderna.

Las sociedades de pensamiento se constituyeron en instancias promotoras de obras y políticas que sentaron las bases para el tránsito hacia una sociedad con valores y principios sustentados en la urbanidad, civilidad y progreso, bajo las premisas que orientaba la modernidad. Estas asociaciones tuvieron en el Estado a un aliado que promovió el ejercicio de una política pública, donde los principios que sustentaron el nacimiento de esas formas asociativas se constituyeron en los ejes orientadores de un accionar que encontró en los desamparados el pretexto para poner en ejecución iniciativas de diferente índole, en el cual sector oficial y privado se coordinaron, impactando de manera favorable el ejercicio del poder dentro de la realidad zuliana.

En esta perspectiva, encontramos diferentes modalidades asociativas como los Gremios, Cooperativas, Sociedades Económicas de Amigos del País, Juntas de Fomento, Cámaras Comerciales, y otras, organizaciones que se constituyeron en instrumentos para inducir a los funcionarios del Estado a compartir el ejercicio del poder con las elites del espacio público zuliano en los ámbitos: económico, social, político y cultural.

La prédica filantrópica de los comerciantes y la intelectualidad marabina respondía a la necesidad de acercarse a las directrices del capitalismo mundial, en relación a la defi- 
nición de patrones de comportamiento que debían regir en una sociedad en tránsito hacia un estadío de modernidad. El instrumento diseñado paras llevar adelante esa predica lo constituye la creación de organizaciones que conllevan a entender al asociacionismo como una práctica que posibilitaría el acceso a las decisiones del Estado. Surge una gran variedad de asociaciones con fines y características muy diversas: que dinamizan el espacio público, mediante la ejecución de obras e iniciativas asistencialistas con la inversión de capitales privados y estatales.

En definitiva, la consolidación del fenómeno del asociacionismo es un producto de la modernidad, en el contexto de la expansión del capitalismo como herramienta de convivencia y confrontación de ideas dentro del liberalismo. "La cultura asociativa penetra gracias a los pedagogos que la difunden: la burguesía rural y urbana, propietarios agrarios, periodistas, ingenieros, alcaldes, concejales, sacerdotes, maestros, médicos, veterinarios, boticarios, notarios" (Maza, 2003, p. 13).

Este proceso promueve una nueva concepción de la realidad en el imaginario marabino, emergiendo un tipo de vocabulario propio de esa naciente cultura asociativa vinculada a las corrientes liberales y positivistas, a saber: Orden, Progreso, Patria, Civilidad, Moral Pública, entre otras. Se construye un discurso que justifica la necesidad de socorrer al semejante a través de iniciativas de utilidad pública, redefiniendo los patrones de comportamiento que caracterizaban al individuo de la época. Numerosas fueron las comunicaciones entre actores públicos y privados donde se palpan esas categorías que develan el esquema de pensamiento de los habitantes de la región; observemos un ejemplo:

Logia Regeneradora № 6.

Comunicación al Dr. Regulo Oliveros, 1er vicepresidente Encargado del Ejecutivo del Estado.

Inspirada la asociación masónica en los santos principio de orden y moralidad, de progreso y patriotismo que hacen grandes a los pueblos, esta logia ha creído conveniente ofrecerles su leal cooperación como magistrado fiel del Zulia en todo cuanto se relacione con la alta misión que desempeñáis, con los fines y tendencias de esta secular institución (Archivo Histórico del Estado Zulia, 1904, p. 1).

En el contexto del auge comercial que imperaba en la ciudad, la posibilidad de agrupar a sus actores pasa a representar una prioridad, se reconoce el derecho a asociarse con objetivos económicos, sociales y políticos, además de mecanismo de protección para sus miembros. La Cámara de Comercio de Maracaibo, que tuvo como antecedente inmediato al Gremio Mercantil fundado en 1878, se constituye en un intento de los grupos económicos por adquirir una mayor incidencia en todo aquello que se vinculara con iniciativas de carácter público. La misma es fundada el 11 de mayo de 1894; en el seno de este cuerpo se estudian las materias que requieren especial atención en provecho de los intereses comerciales: se emiten opiniones en casos concretos sometidos a su consideración, o que de modo propio se cree en el deber de "investigar; gestiona cuanto contribuye a allanar los inconvenientes que se presentan en la marcha regular del comercio, siempre con la discreción y mesura de quien se cuida de sus condiciones de imparcialidad y de procedimientos serios y comedidos" (Rivas, 1962, p. 133). 
A lo largo del siglo XIX se gesta la aparición de nuevos actores sociales que impulsan la lucha por consolidar la idea de nacionalidad. Uno de los instrumentos predilectos de estas iniciativas integracionistas lo constituye la organización de asociaciones de diversos tipos, inspiradas en las pautas de la ilustración: utilidad pública y bien común. En este sentido comienzan a aparecer nuevos lugares tanto públicos como privados, en los que se promueve el igualitarismo y se busca el bien común, tales como: logias, sociedades de lectura y tertulias. El fin de estas sociedades era "la confrontación de las ideas y la promoción del pensamiento liberal ilustrado. Ejemplo de estas nuevas formas de sociabilidad lo constituyó la sociedad patriótica, primer centro de difusión y discusión de las ideas filosóficas modernas en el país" (Cabrera, 2004, p. 44).

De acuerdo a la argumentación manejada por la Fundación Polar (1998):

Este proceso adquiere un carácter institucional en 1829 con la instalación en Caracas de la llamada "Sociedad Económica de Amigos del País", por decreto del General José Antonio Páez Jefe Superior, Civil y Militar de Venezuela, como expresión de un modelo surgido en Europa y que se traslada a la América hispana a principios del siglo XVIII. Las sociedades económicas fueron una de las más interesantes formas que adoptó la acción organizada de las élites ilustradas europeas e hispanoamericanas en la segunda mitad del siglo XVIII y primera del siglo XIX. Estas sociedades comenzaron a establecerse como expresión del ambiente intelectual de una época. Fue, en muchos casos, el antecedente inmediato de las sociedades económicas, creadas por iniciativa de los monarcas bajo este mismo espíritu innovador (p. 2).

Ellas congregaban a los hombres ilustrados y prominentes de la sociedad, constituyéndose en una elite intelectual, social y política, deseosa de fomentar el progreso mediante la educación y las leyes. Entre sus miembros encontramos a notables hombres pertenecientes a los diferentes sectores profesionales, intelectuales y económicos: médicos, comerciantes, hacendados militares, abogados, escritores, industriales, artesanos, funcionarios, artistas y educadores. El espíritu de estas sociedades se recoge en sus estatutos, donde queda plasmada la necesidad de reunir a los hombres de sabiduría a fin de realizar los diagnósticos de la realidad y proponer soluciones a las situaciones problemáticas. Sugerencias que eran asumidas por las instancias del poder político; tales instancias se constituyen en antecedente de lo que en adelante serían grupos de presión, organismos asesores o mecanismos de concertación social, vale decir: gremios, sociedades del pensamiento, clubes, cámaras empresariales, juntas de fomento.

El 20 de junio de 1833 se funda la "Sociedad de Amigos del País" en la provincia de Maracaibo, el decreto de creación delimita el marco de las competencias y cualidades de quienes la conformarían de la siguiente manera (Reales Sociedades Económicas Amigos del País, 1883):

La empresa más popular, y de más conveniencia pública, es la de reunir los hombres de inteligencia, poseídos de amor patrio y de un espíritu nacional, bajo un instituto benéfico que procure el bien de todos, restablezca entre nosotros el amor al trabajo y nos estimule a tareas ventajosas y productivas. Persuadido de estos principios he resuelto formar y establecer en esta capital una Sociedad Económica de Amigos del País —(SEAP)—, que en cumplimiento del capítulo $3^{\circ}$, artículo 16, de la ley orgánica de Educación Pública de 18 de marzo de 1826, promueva los progresos de la agricultura, del comercio, de las artes, oficios, población e instrucción (Archivo Histórico del Estado Zulia, 1883, p. 1). 
Esta organización se constituye en instancia difusora de los adelantos que en las áreas del conocimiento y producción se iban alcanzando. En este sentido, la SEAP Maracaibo se planteó como su principal propósito el de proporcionar a los grupos económica e intelectualmente más avanzados un espacio político de reconocimiento a sus aportes científicos, intelectuales y económicos. "La promoción escrita de los progresos alcanzados hasta ese momento se constituyó en un eje de acción primordial asumido por los actores que lideraron aquellas actividades ilustradas de notable incidencia socio-cultural en Maracaibo (Cazzato, 1998, p. 41).

Este tipo de organización inspira la creación de otras modalidades asociativas a partir de la década de 1870 en Maracaibo, circunstancias de índole económico, educativo y político determina la preocupación de los actores del espacio público por generar formas de asociación que propiciaran su participación en las coyunturas políticas de la región, se asume que la posibilidad de incidir en los órganos de toma de decisión pasaba por fomentar gremios y sociedades que les permitieran participar en aquellos temas que afectaran al colectivo, en otras palabras, se comienza a entender el corporativismo como una forma de ejercer el poder dentro del contexto de una filosofía liberal.

El desarrollo intelectual e ideológico experimentado por los marabinos a partir de la década de 1860 vinculado al pensamiento liberal, conduce a la consolidación de este proceso, como manifestación del auge de la educación; en torno a las actividades artesanales, comerciales e industriales que se realizaban en la cotidianidad; la sociedad civil buscó nuevas formas de organización paralelas o por encima de las ya existentes a nivel del país y del Estado, y lo encontró dentro de una legítima tradición hispana: las sociedades. Urdaneta (2001) sostiene que a partir de 1876 se produce una proliferación tal de las mismas que no resulta difícil relacionar este hecho más allá de los usos introducidos por la corriente liberal dominante que le asignó un papel fundamental en la consecución de las metas de progreso y bienestar - con la situación general de crisis en que estuvo sumido el estado Zulia y en especial la ciudad de Maracaibo.

En este contexto surge una gran variedad de asociaciones con fines muy diversos, entre otras:

\section{Sociedades religiosas}

Sociedad Progreso Católico de Cristo de Aranza, Sociedad de Sagrado Corazón de Jesús en la Iglesia Matriz, Sociedad Pía Unión de N. S. del Carmen, Sociedad Hijos de Chiquinquirá, Sociedad Culto a la Santa Cruz, Compañía de Jesús, Culto de María, Vínculo Católico, Rosario de María, Nueva Congregación, Carmelo.

Esta modalidad asociativa se nutre de la idea de "filantropía", nacida en los ambientes ilustrados del siglo XVIII en el seno de la francmasonería, partiendo de un supuesto amor al género humano. Desde el siglo XVI se crean en Venezuela una serie de instituciones e iniciativas de asistencia social, tales como las "Cajas de Comunidad", hospitales atendidos por los hermanos de San Juan de Dios, y otras obras de asistencia a huérfanos, desvalidos, enfermos, niños, ancianos, pobres, promovidos por institutos religiosos, especialmente 
femeninos. Es a finales del siglo XVIII cuando esta modalidad asociativa gestada desde la experiencia de las cofradías europeas irrumpe en Venezuela, siendo el siglo XIX donde las mismas alcanzan su mayor auge en Maracaibo.

\section{Sociedades para rendir homenaje a personalidades}

Sociedad Vargas, Sociedad Urdaneta, Sociedad Baralt, Sociedad Bolívar, Sociedad Honor y Gloria al invicto Guerrero de las pampas para celebrar el centenario de Páez, Sociedad Vargas, Sociedad Colón.

Las mismas desempeñaron un relevante papel en la instauración de un sentido de amor a la patria durante los gobiernos de Antonio Guzmán Blanco, a partir de la puesta en ejecución de una política de conmemoraciones de fechas patrias y natalicias de los héroes. Se constituyeron en brazos ejecutores de esta política, asumiendo la responsabilidad de organizar eventos para darle realce a tales celebraciones, permitiéndose la potestad de sugerir la construcción de plazas y parques, las cuales eran aprobadas por el Estado y dada a los mismos la posibilidad de diseñar, coordinar y supervisar su realización.

\section{Sociedades para el fomento de obras}

Sociedad Mutuo Auxilio, Sociedad Benéfica del Zulia, Sociedad Agrícola, Sociedad Protectora de la Juventud para la Instalación de un Instituto Secundario, Sociedad Latinoamericana para la Construcción de una biblioteca, Asociación Compañía Nuevo Cementerio, Sociedad Gimnasio de la Juventud.

Fueron sociedades pensadas con el propósito de influir sobre el ejecutivo para que éste aprobara la construcción de obras de carácter público; al lograrse tal cometido sus integrantes adquirían protagonismo en el diseño y ejecución de la misma. Se crean, en consecuencia, las juntas de fomento encargadas de fiscalizar su desarrollo, conformadas por individuos ligados al comercio y la industria agrupados en estas modalidades asociativas.

\section{Sociedades Asistencialistas}

Sociedad Auxiliar de Panaderos, Sociedad Protectora de sus Miembros, Sociedad del Santo Sepulcro, Sociedad Alianza Democrática, Asociación de Monte Piedad, Sociedad Auxiliar de la Juventud, Sociedad Protectora de Animales, Sociedad Auxiliar de Artesanos.

Fundadas con el objetivo de asistir a aquellos ciudadanos que requiriesen atención en determinadas circunstancias: auxilio financiero, préstamos, créditos, pólizas de seguros, apoyo material. Teniendo la particularidad que dichas ayudas se orientaban a individuos con una situación económica no tan desfavorable, pues, como es lógico suponer, los grupos excluidos de la sociedad difícilmente podían acceder a tales beneficios que implicaba poseer bienes de riqueza para honrar sus pagos. 


\section{Sociedades Económicas}

Sociedad Económica de Amigos del País, Gremio Mercantil, Cámara de Comercio de Maracaibo, Asociación Compañía de Seguros de Vida, Asociación La Caja de Ahorro, Amigos del Progreso, Banco de Maracaibo, Gimnasio del Progreso, Esperanza en el Porvenir, Casa de Empeño de Monte Piedad, Caja de Ahorros de la Sociedad Mutuo Auxilio.

Desde 1870 se propicia en Maracaibo un incipiente desarrollo industrial, con el surgimiento de fábricas; es promovida la recuperación de este ramo a partir de la fundación de sociedades que se encargarían de realizar diligencias orientadas a convencer a grupos privados y sector oficial de la necesidad del apoyo a la misma. Se buscaba, con esa actitud, ganar adeptos que aportaran la inversión necesaria para la apertura de determinada industria en algún ramo específico de la economía.

En esta perspectiva, se introduce en las prácticas cotidianas de los marabinos una cultura que promueve la participación como mecanismo para alcanzar la transformación cualitativa de la sociedad, integrándose en iniciativas concretas los intereses públicos y privados. La asociación es el camino para viabilizar la posibilidad de adelantar una propuesta de desarrollo, donde los grupos más favorecidos en lo intelectual, ideológico, económico y político, se tradujeran en la vanguardia de todo este proceso.

Maracaibo es una ciudad que a lo largo de la segunda mitad del siglo XIX comienza a despertar ante las nuevas corrientes filosóficas, ideológicas, tecnológicas, políticas y culturales que predominaron en el mundo, a partir de la penetración de los valores de modernidad que introdujo el capitalismo como sistema en expansión. Los actores del espacio público marabino entendieron la importancia de la asociación como herramienta para la participación en los diferentes ámbitos de la vida en sociedad y su incidencia en decisiones que afectaban al colectivo, en relación a la promoción de iniciativas que propugnaban un bienestar común, facilitando la posibilidad de acceso a las altas esferas políticas.

Cualquier motivación era válida para justificar la fundación de una sociedad, encontrando entre las numerosas asociaciones surgidas en el período 1880-1910, variadas argumentaciones que condujeron a ciudadanos, pertenecientes al comercio, industria e intelectualidad, a la instalación de organizaciones sustentadas en un discurso altruista y modernizador. Se visualiza en la adopción de esta cultura asociativa la necesidad de sus promotores de llenar el tiempo de ocio, adelantando un supuesto bienestar al resto de la población con la generación de privilegios económicos y políticos.

Esa preocupación aparenta expresar un espíritu de sensibilidad hacia aquellos individuos que se encontraban en situación de penuria, y, posiblemente, en algunos casos era la circunstancia que propiciaba la creación de asociaciones de carácter piadosas para socorrer a los excluidos de las riquezas, teniendo en cuenta que la pobreza expresada en una condición extrema de mendicidad chocaba con las aspiraciones de las elites de transformar la realidad marabina en una sociedad civilizada, donde los valores de urbanidad y civilidad prevalecieran como estilo de vida. 
Esa voluntad asociativa avanza hacia la configuración de organizaciones que agrupan a los gremios existentes dentro de la realidad zuliana; en algunos casos la conformación de asociaciones lejos de mancomunar esfuerzos con los funcionarios públicos para la promoción de iniciativas asistencialistas, planteaba enfrentar a los órganos del Estado central para exigir el respeto a nuestros derechos autonómicos. Constituía evidencia del nivel de conciencia que habían alcanzado los zulianos y sus prácticas asociativas, cuando éstas son empleadas como arma de lucha en la búsqueda de reivindicaciones regionales que los impulsaba a enfrentarse al poder político nacional.

En consecuencia, en la estructuración de esa cultura asociativa del siglo XIX vamos a encontrar la presencia de tres elementos que denotan el carácter de este tipo de organización, a saber: una relación muy estrecha con las ejecutorias del Estado, un discurso altruista civilizador y moralista sustentado en las corrientes modernas del pensamiento y funcionarios públicos formando parte de las mismas. Estos detalles se pueden corroborar en la siguiente referencia de la época:

Dr. Alejando Andrade.

La Sociedad Auxiliar de Artesanos de la que U forma parte tan importante, ha visto con reconocimiento los valiosos servicios que $U$ siempre ha prestado en momentos muy oportunos; siendo hoy su estado pecuniario no muy halagador, ocurre, como otras veces lo ha hecho, en demandas de su generosa protección para la fiesta aniversario que tendrá lugar el día dos del entrante mes. Bien comprenderá el hijo desinteresado la cooperación que su madre necesitada al hacer la exigencia, así como bien conoce la madre al hijo que ha de pedir su apoyo.

Satisfecha la corporación de la acogida que ha de tener su solicitud, me encarga dignificar una vez más al honorable colega las protestas de su sincero agradecimiento, y la singular deferencia y estima de un humilde S y colega (Archivo Histórico del Estado Zulia, 1897, p. 1).

En definitiva, el período histórico comprendido entre 1880 - 1910 constituyó un período de significativa trascendencia para la dinamización de un conjunto de procesos económicos, sociales y culturales, apalancados por el desarrollo ideológico de los actores del espacio público marabino en torno a las concepciones políticas predominantes en otros contextos territoriales de la época, con su inevitable impacto en el forjamiento de avances en diferentes órdenes de la convivencia colectiva, consustanciada con las ideas de progreso y civilidad que rondaban en la mente de sus protagonistas empoderados. Como evidencia de lo afirmado Urdaneta y Pineda (1988) sostienen que:

Hacia la última década del siglo XIX e inicios del XX, la legislación sobre materias fundamentales como justicia, rentas del estado, instrucción pública, régimen político, división territorial fue anualmente revisada y reformada. Se observa una mayor preocupación por perfeccionar los instrumentos jurídicos legales que permiten un mejor funcionamiento de la sociedad y el Estado. Su complejidad creciente exigía de medidas político-administrativas, sociales y económicas más eficaces que optimizaran la convivencia de los zulianos, decisiones más acordes con el progreso que compartían (p. 25). 
En ese contexto la investigación posibilita esclarecer el significado asignado al ejercicio del poder instaurado en aquel tiempo histórico, donde según Apreda (2004), trasciende de una visión reduccionista para aplicarlo en un contexto más amplio, asociado a términos de producción que sobrepone la libertad a la represión, la promoción a la prohibición y la recompensa al castigo. En esta óptica, se insertan las asociaciones marabinas del siglo XIX como instrumentos de participación de los actores sociales en las decisiones que correspondían al Estado, y que proyectaban la necesidad de propiciar el bien común en la población; así en términos generales se visualizó la cultura "como un instrumento de lucha y empoderamiento" (Beresñak, 2011, p. 16)

\section{CONCLUSIONES}

El ejercicio del poder en la región histórica marabina decimonónica dejó de ser una competencia exclusiva de los funcionarios públicos para trasladarse a diferentes esferas, donde los individuos conforman sociedades: gremios, clubes, juntas de fomento, a través de las cuales le asignan un sentido creador al ejercicio del poder que detentaban. Los actores agrupados acudieron al derecho de asociación para instalar organizaciones que rompieran con una cultura política donde los ciudadanos no poseían espacios para la incidencia en las decisiones que se tomaban a nivel público. Esta realidad conduce a visualizar el establecimiento de un esquema del ejercicio del poder compartido entre los líderes del comercio agrupados en sociedades y los funcionarios oficiales, configurando el diseño de una nueva concepción del espacio público para los negocios, la atención al semejante y el adelanto de una política de modernización de todas las estructuras con la propagación de los patrones culturales que instruyeron las inversiones extranjeras.

Así las posibilidades de empoderamiento de los actores económicos se traslada a cada una de las esferas de la vida y se reproducen diversas formas de ejercitarlo: el desarrollo de una opinión pública, el diseño de políticas para el uso y disfrute de los espacios públicos, el papel de la familia como agente de formación espiritual, el surgimiento de una conciencia autonómica regional y el diseño de instrumentos moralizadores de la conducta social. Se generan, en consecuencia, redes de poder que involucran a buena parte de los integrantes de la sociedad, estableciéndose variadas formas de relacionamiento social, donde el mismo se asume como las diversas partículas en las cuales se manifiestan las expresiones del accionar individual y colectivo.

Fueron variadas las motivaciones que impulsaban a los marabinos de la época a buscar la reunión de individuos en sociedades y gremios como estrategia para asumir posiciones de dirección, propiciando desde allí la generación de un conjunto de iniciativas que posibilitaban, a su entender, un desarrollo socio-cultural que se correspondía con la búsqueda de una realidad apuntalada bajo los principios de la civilidad que acompañaba al imaginario de los hombres de negocios e intelectualidad de la época.

En este orden de ideas, los grupos que lideraban los procesos políticos y económicos comienzan a expresar puntos de vista que van a tener influencia en el desarrollo histórico marabino, favorecido por dos iniciativas que impulsan el despertar ideológico de los zulianos; esto es,el surgimiento de los gremios y sociedades del pensamiento como 
espacios para el debate en torno a la dinámica de funcionamiento de la sociedad regional, y la divulgación de esas ideas al colectivo a través del florecimiento de la prensa como canal natural para la información. Se materializa una simbiosis Estado-sector privado, expresada en relaciones de diversos tipos que terminan por convertir a los integrantes de las asociaciones en factores dinamizadores de las políticas del sector público para la atención del ciudadano, apuntalada en la generación de iniciativas de diversa índole para el favorecimiento del bienestar colectivo.

Queda para la discusión considerar si esa aparente preocupación de los prominentes hombres de las ciencias, las artes, el comercio y la industria por el prójimo, reflejaba un verdadero sentido de sensibilidad social por la suerte de aquellos individuos que no habían alcanzado satisfacer los requerimientos básicos para una vida digna, con el combate de males sociales como el alcoholismo, la mendicidad y la prostitución, representando así la expresión de una real conciencia social acerca de la necesidad de eliminar esos males, o, si por el contrario, esta actitud no denotaba más que el interés por favorecer la generación de privilegios económicos para consolidar el control social sobre el resto de la sociedad, tanto en el orden material como en el plano de las ideas.

La revisión de las fuentes históricas verifican la presencia de ambas intenciones en las actuaciones corporativas de la época, emergiendo la idea que esa predica filantrópica respondía a la necesidad de adecuar la realidad marabina a las pautas que imponía el capitalismo mundial, en relación a la definición de los patrones de comportamiento que debían regir en una sociedad que se preciara de haber transitado hacia un estadío de modernidad, como era la aspiración de los hombres de negocios y ciencias del momento. Se visualiza, en consecuencia, el establecimiento de redes de poder que involucraron a buena parte de la población, donde el accionar conjunto de los actores públicos y privados logra cohesionar la ejecución de iniciativas que plantean el mejoramiento de la convivencia ciudadana, en particular en los sectores más humildes. En este caso, se instaura una filosofía de acción que entiende que satisfacer las necesidades colectivas posibilitaba, a su vez, la generación de ingresos y privilegios a las elites económicas, por lo cual el beneficio de esas políticas iría a favorecer al conjunto de la población.

\section{REFERENCIAS}

Apreda, G. (2004). La Concepción de Sujeto en Michel Foucault. La Plata: Universidad Nacional de la Plata Argentina.

Archivo Histórico del Estado Zulia. (1904). Logia Regeneradora N 6. [Comunicación al Dr. Regulo Oliveros]. Maracaibo: Tomo 33, Legajo 12.

Archivo Histórico del Estado Zulia. (1897). Sociedad Auxiliar de Artesanos. [Comunicación dirigida al Dr. Alejando Andrade]. Maracaibo: Tomo 14, Legajo 21.

Archivo Histórico del Estado Zulia. (1883). Fundación sociedad de Amigos del País. [Comunicación]. Maracaibo: Tomo, Legajo . 
Beresñak, F. (2011). Michel Foucault y su metodología histórico-filosófica. Revista digital Synesis, (2), 8-16.

Bernaus, M. (2000). Barcelona y los Gremios. [Online]. Disponible en https://www.liceus. com/barcelona-y-los-gremios/

Cabrera, G. (2004). Fiestas Nacionales y Opinión Pública en Maracaibo (1834-1862). [Trabajo Magistral]. Universidad de Zulia, Maracaibo, Venezuela.

Calderón, M. (2013). Hacia una Pedagogía Hermenéutica desde una Hermenéutica de la Educación. [Disertación licenciatura]. Pontificia Universidad Católica del Ecuador, Quito, Ecuador. Disponible en http://repositorio.puce.edu.ec/handle/22000/7067

Cardozo, G. (1991). Maracaibo y su región histórica. El circuito agro-exportador 18301860. Maracaibo: Universidad Del Zulia.

Cazzato, S. (1998). Elite, Poder y Espacio Público en las SociedadesMaracaiberas (18331846). [Tesis Magistral]. Universidad del Zulia. Maracaibo, Venezuela.

Dilthey, W. (1949). Introducción a las ciencias del espíritu. [2 Ed.]. México, D.F.: Fondo de Cultura Económica.

Fundación Polar. (1998). Diccionario Multimedia de Historia de Venezuela. Caracas: Empresas Polar. Disponible en https://bibliofep.fundacionempresaspolar.org/dhv

Gadamer, H. (2000). Verdad y Método. Salamanca: Sígueme.

Guerra, F. (1998). Modernidad e independencias. Ensayos sobre las revoluciones hispánicas. México, D.F.: MAPFRE.

Maza, E. (2003). Asociacionismo en la España Contemporánea. Valladolid: Universidad de Valladolid.

Ortiz, A. (2015). Maracaibo. Ciudad de 3 Fundaciones. Cabimas: UNERMB.

Rivas, J. (1962). El Comercio de Maracaibo. Maracaibo: Editorial del Lago.

Rubio, L. (2007). Honor e identidad en Maracaibo a fines del siglo XIX. Opción, 23(52), 25-44. Disponible en https://produccioncientificaluz.org/index.php/opcion/article/ view/6397

Reales Sociedades Económicas de Amigos del País. (1883). Decreto de Creación de la Sociedad. [Online]. Disponible en http://www.amigosdelpais.es/quienes-somos-2/

Urdaneta, A. y Pineda, N. (1988). Acuerdos, Leyes y Decretos de la Asamblea Legislativa del Estado Zulia. 1857-1908. Maracaibo: Asamblea Legislativa del Estado Zulia/Centro de Estudios Históricos./Universidad del Zulia. Disponible en https://www.sudoc. fr/107977761

Urdaneta, A. (2001). Federalismo y Gobierno Federal en el Zulia (1811-1870). [Tesis doctoral]. Universidad del Zulia, Maracaibo, Venezuela. 
Jairo Enrique Boscán Fernández es Licenciado en Educación con Mención en Ciencias Sociales del Área de Historia en la Universidad del Zulia (Venezuela). Magíster Scientiarum en Historia de Venezuela de la Universidad del Zulia (Venezuela). Diplomado de Estudios Avanzados en Gestión y Desarrollo Turístico Sostenible de la Universidad de Málaga (España). Doctor en Educación de la Universidad Experimental "Rafael María Baralt” (UNERMB) (Venezuela). https://orcid.org/0000-0003-0157-5378

Xiomara Emilia Guanipa de Dávila es Licenciada en Educación, mención Ciencias Sociales, Área Geografía de la Universidad del Zulia (Venezuela). Magíster Scientiarum en Docencia para la Educación Superior de la UNERMB (Venezuela). Diplomado de Estudios Avanzados en Gestión y Desarrollo Turístico Sostenible. Universidad de Málaga (España). Doctora en Educación de la Universidad Experimental "Rafael María Baralt" (UNERMB) (Venezuela). https://orcid.org/0000-0002-8890-0606 